\title{
Social Representations of Violence against the Elderly
}

By Maria-Adriana Coler, Manuel Lopes and Antonia Silva.

Published by The International Journal of Aging and Society

Format

Price

\begin{tabular}{llr}
\hline Article: Print & \$US10.00 & Order \\
\hline Published online: December 8, 2016 & \$US5.00 & Order \\
\hline
\end{tabular}

The repercussions of violence on the mental, social, and physical well-being of the elderly are some of the most challenging problems in public health today. Using a qualitative design, we conducted a study in Portugal and the United States that applied both descriptive and comparative methods in order to understand the social representations of violence against the elderly. Utilizing the Theory of Social Representations, we explored the perspectives of the elderly, their families, and healthcare professionals on the subject of violence against the elderly. The data on which the findings were based were obtained in two very different cultural contexts, yet the representations of violence against the elderly revealed no significant cross-cultural differences. However, conceptualizations regarding expectations of care and protection for the elderly proved to be distinct. We discussed concerns about the general attitudes of tolerance toward violence, including those of the elderly who selfidentified as eventual victims. Violence against the elderly was portrayed as a part of old age and also somehow was justified by it. The results also indicated the need to better prepare healthcare professionals and society in general to deal with the consequences of the problem and not, as we would like to report, to prevent it from happening.

Keywords: Elderly Violence, Social Representations

The International Journal of Aging and Society, Volume 7, Issue 3, pp.27-34. Article: Print (Spiral Bound). Published online: December 8, 2016 (Article: Electronic (PDF File; 605.026KB)).

\section{Maria-Adriana Coler}

Adjunct Professor, Psychology Department, University of Bridgeport, Manchester Community College, Bridgeport, Connecticut, USA

\section{Manuel Lopes}

Director, School of Nursing, University of Evora, Evora, Portugal

\section{Antonia Silva}

